\title{
Comunicação clínica no internato: habilidade em interface com o currículo integrado e orientado por competência
}

\section{Clinical communication in medical practice internship: articulating the skill to an integrated and competence- oriented curriculum}

\author{
Ana Glaucia Paulino Lima' (1) | anagplima@gmail.com \\ Danielle Abdel Massih Pio ${ }^{1}$ (D) danimassihpio@hotmail.com \\ Ana Carolina Nonato' 1 (D) noto.anacarolina@gmail.com \\ Mara Quaglio Chirelli' (1) marachirelli@gmail.com \\ Roseli Vernasque Bettini' ${ }^{1}$ (D) roselibett@gmail.com
}

\begin{abstract}
RESUMO
Introdução: A comunicação clínica é um instrumento de interação entre profissionais e destes com os usuários, importantíssimo para assegurar o cuidado integral dos indivíduos. A complexidade das demandas biopsicossociais dos usuários deve ser compreendida e trabalhada por meio de habilidades desenvolvidas para além do conhecimento técnico e biomédico, com formação mais ampliada em relação ao ser humano. No currículo de uma instituição de ensino superior do interior paulista, a comunicação clínica é competência esperada do estudante em todos os cenários da graduação. No internato médico, em especial, é importante que a prática da comunicação seja trabalhada integradamente, considerando os aspectos biopsicossociais do sujeito relacionados ao cuidado; todavia, a literatura demonstra que essa habilidade é explorada superficialmente na formação, acarretando dificuldade de sua efetivação. Desse modo, parte-se do pressuposto de que há diferentes compreensões acerca do conceito de comunicação clínica e de sua articulação teórico-prática entre docentes e discentes, sendo preciso analisar a formação no internato acerca destes. Objetivo: Assim, objetivou-se questionar como professores e estudantes do internato de um curso médico compreendem o processo de ensinoaprendizagem acerca da comunicação clínica em um currículo integrado e orientado por competência na matriz dialógica.

Método: Trata-se de um estudo qualitativo que contou com a participação de 11 estudantes da quinta série, 12 estudantes da sexta série e nove professores do internato. As entrevistas foram semidirigidas e realizadas a partir de um roteiro de entrevista, sendo posteriormente transcritas e submetidas à análise de conteúdo, modalidade temática.

Resultado: Três categorias emergiram do conjunto de concepções e características dos temas comunicação clínica e currículo: 1. “O que envolve a comunicação clínica", 2. "Desenvolvimento da comunicação clínica na graduação" e 3. "Proposições para a formação de estudantes e professores no internato". Pôde-se observar o entendimento acerca do conceito de comunicação clínica e sua importância na formação dos estudantes, porém evidenciou-se dificuldade de desenvolvimento na formação devido ao desconhecimento do currículo, sobrecarga discente e desvalorização docente. Conclusão: O estudo contempla a comunicação clínica no internato e possibilidades de reflexão acerca de lacunas citadas pelos estudantes e professores. Palavras-chave: Comunicação em Saúde; Docentes; Educação Médica; Estudantes de Medicina; Internato e Residência.
\end{abstract}

\section{ABSTRACT}

Introduction: Clinical Communication is an instrument for interaction between professionals and between them and users, being extremely important to ensure integral care. The complexity of the users' biopsychosocial demands must be understood and worked through skills developed beyond the technical and biomedical knowledge, including a more extensive training in relation to the human being. In the curriculum of a medical school institution in the interior of São Paulo, Clinical Communication is a skill expected of the student in all undergraduate scenarios. During medical internship, it is important that communication practice be developed in an integrated fashion, considering the biopsychosocial aspects of the subject under care; however, the literature demonstrates that this skill is superficially explored in training, causing difficulty for its effectiveness. Thus, it can be assumed that there are different understandings about the concept of Clinical Communication and its theoretical-practical articulation between teachers and students, being necessary to analyze this educational process during internship.

Objective: Thus, the objective was to question how teachers and students from a medical course internship understand the teaching-learning aspects about Clinical Communication in an integrated and competence-based curriculum.

Method: This was a qualitative study, which included eleven 5th-year medical students, twelve 6th-year medical students and nine internship teachers. The interviews were semi-directed and carried out based on an interview script, which were later transcribed and submitted to the analysis of content, thematic modality.

Results: Three categories emerged from the concepts and characteristics of the topics "Clinical Communication" and "Curriculum": 1) What involves clinical communication; 2) Development of clinical communication during the undergraduate course and 3) Proposals for the training of internship students and teachers. It was observed that the participants understood the concept of Clinical Communication and its importance for the students' training, but also that it is difficult to develop this training due to the lack of knowledge about the curriculum, student work overload and teacher devaluation.

Conclusion: The study considers the development of Clinical Communication skills of internship students and the possibilities for reflection on gaps mentioned by students and teachers.

Keywords: Health Communication; Faculty; Medical Education; Medical Students; Internship and Residency.

${ }^{1}$ Faculdade de Medicina de Marília, Marília, São Paulo, Brasil.

Editora-chefe: Rosiane Viana Zuza Diniz. ～～Editor associado: Roberto Zonato Esteves.

Recebido em 26/01/21; Aceito em 27/04/21. | Avaliado pelo processo de double blind review. 


\section{INTRODUÇÃO}

A comunicação é um instrumento de interação entre dois ou mais indivíduos, processo contínuo, fluido, em que as ideias dos envolvidos devem ser descobertas e compreendidas por ambos ${ }^{1}$.

Nos serviços de saúde, a comunicação clínica caracterizase como um processo muito importante para assegurar o cuidado integral do usuário. Para que seja efetiva, é fundamental que haja disposição dos trabalhadores em participar ativamente desse movimento, intencionando melhor qualidade das relações interpessoais por meio de respeito e empatia².

Os serviços de saúde são, muitas vezes, permeados pelo tecnicismo. Esse "ambiente estranho" pode causar diversas emoções no usuário, como medo do desconhecido e ansiedade devido à sua situação, que afeta diretamente sua autonomia. Caso o profissional não possua olhar ampliado, a comunicação será frágil, pois estará direcionada à patologia e não ao sujeito, tornando o cuidado ainda mais fragmentado ${ }^{3}$.

A complexidade das demandas biopsicossociais apresentadas pelos pacientes deve ser compreendida e trabalhada por meio de habilidades desenvolvidas para além das fixadas no conhecimento técnico e biomédico, com formação mais ampliada em relação ao ser humano ${ }^{4}$. Dessa forma, a humanização em saúde apresenta-se como demanda crescente ${ }^{3}$.

A comunicação clínica é a ferramenta que pode influenciar os envolvidos significativamente, trazendo representações sobre sua situação e repercutindo na relação entre estes e os profissionais, com maior adesão ao tratamento e redução do sofrimento físico e emocional ${ }^{5}$.

Todavia, na prática, há vários fatores que impedem que a comunicação clínica ocorra como deve, como: falta de informação ou predominância de informações técnicas, resultando no afastamento cognitivo entre as partes; pouco investimento de tempo ${ }^{5}$; dificuldade de a equipe de saúde transformar verdades doloridas em informações claras e objetivas; rotina e sobrecarga de atividades e responsabilidades no trabalho, o que minimiza a atenção dispensada às queixas dos pacientes e de seus familiares e impede a escuta qualificada, imprescindível para o cuidado integral destinado ao indivíduo; sentimentos negativos dos profissionais em relação à situação, como ansiedade e angústia ${ }^{2}$. Um dos motivos para tal é falta de experiências formadoras teórico-práticas, o que alerta para a necessidade de se trabalhar essa habilidade por meio dos cursos de formação².

No contexto da educação médica, a comunicação deve ser trabalhada em toda formação do estudante. Desse modo, é importante ressaltar que as Diretrizes Curriculares Nacionais (DCN) do curso de graduação em Medicina, estabelecidas em
$2001^{6}$ e reestruturadas em $2014^{7}$, preconizam, em seu artigo $4^{\circ}$, a necessidade do desenvolvimento de conhecimentos, habilidades e atitudes dos estudantes no que diz respeito à clareza, à empatia e ao sigilo na comunicação verbal e não verbal? .

Essa proposta pedagógica está inserida no currículo integrado e orientado por competência de uma instituição de ensino superior (IES) do interior paulista, cujo objetivo é o processo de formação voltado para a articulação teóricoprática por meio de constante reflexão da realidade vivenciada e da inserção gradativa do estudante em diferentes cenários, a fim de que desenvolva autonomia e domínio de seus desempenhos durante formação profissional ${ }^{8}$. Nesse currículo, a comunicação clínica é competência esperada do estudante em todos os cenários da graduação9.

Para que a habilidade de comunicação seja de fato exercida dentro da proposta do currículo integrado e orientado por competência, o papel do professor é imprescindível nesse processo $^{2,10}$.

Considerando o internato médico, é importante que a prática da comunicação nesse ambiente seja trabalhada conforme propõe o currículo, de forma integrada e observando os aspectos biopsicossociais do sujeito relacionados ao cuidado. Todavia, um estudo com professores e estudantes envolvendo esse aspecto da comunicação demonstrou que essa habilidade foi explorada superficial ou implicitamente, acarretando dificuldade de sua efetivação na prática ${ }^{2,11}$.

Nesse sentido, além da abordagem acadêmica, também há desafios na formação docente, conforme demonstrado por Ferreira et al. ${ }^{12}$, que evidenciam dificuldade do professor com esse quesito dentro do internato, o que traz questionamentos sobre a operacionalização da formação docente e discente conforme as DCN e o Projeto Pedagógico do Curso (PPC). Portanto, parte-se do pressuposto de que há diferentes compreensões acerca do conceito de comunicação clínica e de sua articulação teórico-prática.

Pensando no contexto de saúde, é preciso considerar a representação dos atores nesse ambiente:

- Como o usuário solicita o atendimento?

- Como o profissional enxerga esse indivíduo e enxerga a si mesmo dentro desse cenário?

- Qual é o significado produzido por ambos nessa relação ${ }^{10}$ ?

Assim, é preciso analisar a formação dos estudantes de internato de uma IES do interior paulista acerca do conceito e das habilidades de comunicação clínica.

Este estudo teve como objetivo questionar como professores e estudantes do internato de um curso médico compreendem o processo de ensino-aprendizagem acerca da 
comunicação clínica em um currículo integrado e orientado por competência na matriz dialógica, identificando quais os significados de comunicação clínica para os participantes e quais estratégias utilizadas na formação para trabalhá-la.

\section{MÉTODO}

Trata-se de um recorte de uma dissertação de mestrado profissional realizada em uma IES pública do centro-oeste paulista, que dispõe dos cursos de Medicina e Enfermagem em regime integral, com estrutura anual e seriada e utilizando métodos ativos de ensino-aprendizagem. Possui um total de 480 estudantes de Medicina, dos quais 160 estão no internato. O currículo é integrado e orientado pela abordagem dialógica de competência ${ }^{13}$, e está dividido em três unidades principais: Unidade Educacional Sistematizada (UES), contendo o ambiente de tutorias, cuja aprendizagem está centrada na aprendizagem baseada em problemas; Unidade de Prática Profissional (UPP), que contém os cenários de prática reais e os simulados (Laboratório de Prática Profissional - LPP); e Unidade Eletiva9.

A pesquisa foi submetida ao Comitê de Ética em Pesquisa (CEP) da instituição - Certificado de Apresentação para Apreciação Ética (CAAE) no 13307519.3.0000.5413 -, com aprovação em 3 de junho de 2019 sob Parecer no 3.364.859.

Devido à proximidade com o final da formação e com o resultado da pesquisa de Ferreira et al. ${ }^{12}$, decidiuse investigar a percepção da comunicação clínica para estudantes do internato médico da instituição, sendo esse o critério de inclusão da pesquisa. Em relação aos professores, consideraram-se todas as disciplinas do internato. Os atores foram selecionados aleatoriamente, diversificando apenas cenários de ensino-aprendizagem e séries em que estão inseridos para maior abrangência.

A amostragem da pesquisa deu-se por saturação teórica, ou seja, quando não se podem apreender dados novos a partir de novas entrevistas ${ }^{14}$.

A pesquisa foi iniciada com dois estudos-piloto com um estudante e um professor para avaliar o instrumento de entrevista. Após esse momento, procedeu-se à coleta dos dados. As entrevistas foram previamente agendadas e realizadas individualmentecomosatores deacordocom sua disponibilidade, porém foram transcritas e analisadas separadamente para atingir saturação de cada grupo. Iniciou-se a sessão com levantamento de dados de identificação, e, depois, realizou-se a entrevista por meio da seguinte questão disparadora:

- O que você entende por comunicação clínica, com base na proposta pedagógica do currículo integrado e orientado por competência na matriz dialógica?
Para nortear possíveis intervenções da pesquisadora, utilizou-se um roteiro previamente estabelecido, correspondendo aos objetivos do estudo. As entrevistas foram realizadas exclusivamente pela pesquisadora no período de julho de 2019 a novembro de 2019. Todas foram audiogravadas, com duração média de 15 minutos.

Para preservar a identidade dos participantes, a apresentação dos resultados seguirá este padrão: letra $\mathrm{E}$ para estudantes ou $\mathrm{P}$ para professores, seguidas do número de organização das entrevistas e série(s) em quem se encontram. Por exemplo: E5 - quinta série, E16 - sexta série, P8 - sexta série, P9 - quinta série.

A proposta deste trabalho foi compreender o entendimento dos entrevistados acerca do tema por meio de conhecimentos prévios, experiências e vivências, tanto pessoais quanto profissionais. Para tal, escolheu-se a vertente qualitativa para este estudo.

As entrevistas foram transcritas e submetidas à análise de conteúdo, método exposto por Bardin ${ }^{15} \mathrm{e}$ Minayo ${ }^{16}$. A análise de conteúdo fornece ao leitor informações complementares àquele texto a fim de melhor abrangência e apreciação do conteúdo, e transita pelos elementos que compõem a comunicação, que são: emissor (ou produtor da mensagem) e receptor (indivíduo ou grupo que a recebe ${ }^{15}$ ). Por meio dessa técnica, pode-se acessar o conteúdo das mensagens expressas, com construção e categorização de conhecimentos a partir delas.

A análise de conteúdo na modalidade temática é desenvolvida nas seguintes etapas ${ }^{16}$ :

- Pré-análise: realizam-se sucessivas leituras com diferentes graus de profundidade, buscando obter visão do conjunto, identificar peculiaridades, classificar os dados e esboçar pressupostos norteadores para posterior análise.

- Exploração do material: distribuem-se os trechos conforme a classificação, e realiza-se nova leitura do material para estabelecer diálogo entre os trechos e a literatura, com agrupamento organizado dos dados e identificação das categorias temáticas.

- Tratamento dos resultados, inferência e interpretação: identificam-se os núcleos de sentido emergentes dos trechos que compõem as categorias temáticas, que devem dialogar com os pressupostos norteadores. Além disso, o pesquisador deve se voltar aos marcos teóricos a fim de embasar e interpretar os achados.

\section{RESULTADOS E DISCUSSÃO}

Dos 17 estudantes da quinta série contatados, dois recusaram-se a participar da pesquisa por falta de tempo hábil e 
quatro não retornaram o contato. Com a sexta série, foram feitos 13 contatos, e um não retornou. Participaram 23 estudantes escolhidos aleatoriamente, sendo 11 estudantes da quinta série e 12 da sexta série. Do total, 16 eram do sexo feminino e sete do sexo masculino, com média de idade de 25 anos.

Em relação aos professores, nove participaram da pesquisa, sendo três da quinta série do internato, dois que atuavam somente na sexta série e cinco que atuavam em ambas as séries. Não se obteve recusa de nenhum professor contatado. Seis professores são do sexo masculino, e três, do sexo feminino. A idade média é de 50 anos, com anos de formação variando entre 1979 e 2009. Quanto à titulação acadêmica, há dois doutores, dois mestres e seis especialistas, sendo três docentes da faculdade e seis assistentes de ensino.

Na análise dos dados, após identificação dos núcleos de sentido, as categorias temáticas e as subcategorias emergiram, conforme demonstrado no Quadro 1.

Assim, o conjunto de concepções e características será apresentado por meio de três categorias temáticas que versam sobre a discussão dos temas comunicação clínica e currículo, sendo elas: 1. "O que envolve a comunicação clínica",

2. "Desenvolvimento da comunicação clínica na graduação" e 3. "Proposições para a formação de estudantes e professores no internato".

\section{O que envolve a comunicação clínica}

Para os participantes, a comunicação clínica é um processo dinâmico que trabalha amplamente o desenvolvimento de confiança entre usuários, profissionais e familiares. Segundo os estudantes e os professores, ela ocorre de forma interpessoal entre profissionais da saúde e pacientes, destacando a compreensão de desenvolver atitudes relacionais com os usuários, os próprios colegas e a equipe: "É capacidade de expressar ao paciente e ao familiar respeito de [...] condição clínica do paciente, assim como se comunicar entre próprios profissionais da área que atuam em conjunto [...]" (P9 - quinta série).

No que concerne ao desenvolvimento da comunicação, os estudantes referem-se à habilidade de escuta das demandas do paciente e retorno sobre elas como elementos facilitadores na relação terapêutica; para os professores, trata-se de explicar e orientar com linguagem clara e adaptá-la ao entendimento da pessoa, atingindo maiores possibilidades de comunicação a partir do que o outro compreende: "penso que comunicação começa na escuta [...], é acolher e dar retorno, dar orientação, de construir plano de cuidados em conjunto, de construir hipóteses diagnóstico, raciocínio clínico em cima daquilo que recebeu na primeira escuta" (P5 - quinta e sexta séries).

Estudos mostram que a comunicação clínica que se preocupa com todos envolvidos torna-se indispensável para qualidade dos cuidados em saúde, perpassando aspectos de criar e manter relações terapêuticas com usuários e familiares, e fazer uso da escuta ativa para obter informações, trabalhar habilidades de comunicação e desenvolver relacionamentos interpessoais saudáveise empáticos com outros profissionais ${ }^{17,18}$.

Para se atingir a integralidade do cuidado, estudantes e professores relataram a necessidade de adequação da linguagem utilizada:

\begin{abstract}
[...] tudo envolve você ter não só conhecimento teórico, mas também você conseguir traduzir isso tanto numa linguagem técnica quando você estiver numa discussão com sua equipe quanto numa linguagem mais simples atingindo diversos níveis socioeconômicos e culturais dos pacientes [...] (E14 sexta série).
\end{abstract}

Quadro 1. Categorias temáticas e subcategorias dos estudantes e dos professores sobre comunicação clínica no currículo.

\begin{tabular}{cll}
\hline GRUPO & \multicolumn{1}{c}{ CATEGORIAS TEMÁTICAS } & \multicolumn{1}{c}{ SUBCATEGORIAS } \\
\hline & $\begin{array}{l}\text { 1. O que envolve a comunicação clínica: } \\
\text { participantes e habilidades }\end{array}$ & $\begin{array}{l}\text { 1a. A comunicação nas relações interpessoais } \\
\text { 1b. Habilidades envolvendo a comunicação }\end{array}$ \\
$\begin{array}{l}\text { 2. Desenvolvimento da comunicação clínica na } \\
\text { graduação }\end{array}$ & $\begin{array}{l}\text { 2a. Fortalecimento da comunicação ao longo dos anos } \\
\text { 2b. Fragilidade da comunicação ao longo dos anos } \\
\text { 3. Organização do internato }\end{array}$ & $\begin{array}{l}\text { 3a. Fragilidades da organização do internato } \\
\text { 3b. Proposições para o processo ensino-aprendizagem } \\
\text { no internato }\end{array}$ \\
\hline & $\begin{array}{l}\text { 1. O que envolve comunicação clínica: } \\
\text { desenvolvimento e importância }\end{array}$ & $\begin{array}{l}\text { 1a. O desenvolvimento da comunicação } \\
\text { 1b. Importância da comunicação }\end{array}$ \\
& $\begin{array}{l}\text { 2. Desenvolvimento da comunicação } \\
\text { 2línica na graduação de Medicina }\end{array}$ & $\begin{array}{l}\text { 2b. Fragilidade da comunicação na graduação } \\
\text { 2c. A comunicação na prática pedagógica }\end{array}$ \\
& $\begin{array}{l}\text { 3. Proposições para a formação de estudantes e } \\
\text { professores no internato }\end{array}$ &
\end{tabular}


A preocupação com a linguagem utilizada pode ser observada nos profissionais envolvidos na formação, pois, na prática, eles constatam déficit no repertório comportamental em relação ao desenvolvimento da comunicação, quando predomina o uso de "linguagens técnicas" com os pacientes. Tais comportamentos apresentam-se como nichos para grandes discussões sobre atuação nesse cenário ${ }^{19}$.

Ainda sobre todo cuidado na comunicação como ferramenta de mudança, adesão e vínculo, os professores citam conceitos como empatia a fim de promover mudança na vida do paciente: "Comunicação clínica também é relacionada com empatia [...]. Quando você entende o outro como ser humano idêntico a você, que sofre com o que ele vai escutar, [...] você faz comunicação melhor, mais humana" (P7 - sexta série).

Observa-se efeito positivo em usuários que são tratados empaticamente, mostrando maior adesão ao tratamento, desenvolvimento de confiança e segurança com profissional, maior satisfação no serviço de saúde e nos cuidados prestados a ele e/ou ao seu familiar, com melhora no prognóstico. Já para os profissionais, o ganho quando se adota postura empática nesse ambiente está relacionado a menores índices de depressão, burnout (estresse laboral) e maior satisfação no trabalho ${ }^{20}$.

Tanto os estudantes quanto os professores entendem a comunicação clínica como movimento dinâmico que deve ser colocado em constante prática no ambiente de saúde. Observase que ambos se preocupam com a linguagem utilizada a fim de atingir entendimento e compreensão de todos envolvidos.

\section{Desenvolvimento da comunicação clínica na graduação}

Acerca dessa categoria, os estudantes destacam o olhar biopsicossocial e o estímulo à comunicação no início da graduação. Referem ser um conceito bem trabalhado nos primeiros anos do curso, especialmente no cenário do LPP, que conta com psicólogo, e também por meio das tutorias, nas atividades da UPP e entre pares e com os usuários, percebendo o quanto a inserção precoce na prática colaboram para o desenvolvimento da comunicação: "desde o início a gente já consegue começar estabelecer essa comunicação nos diferentes âmbitos, né?, seja com paciente lá no início do primeiro ano [...], seja com [...] equipe do posto de saúde [...], com nossos colegas" (E23 - sexta série).

Os estudantes destacam o desenvolvimento da comunicação clínica no decorrer da graduação como evolução durante anos por meio da inserção na prática, utilizando esse aprendizado no internato.

Eu acho que tudo é parte de evolução. [...] no primeiro e no segundo ano, a gente tinha algum contato também com paciente mais prolongado, só que [...] lá a gente estava mais pensando na questão da saúde coletiva, em orientações, em prevenção [...]. O que gente fez do primeiro ao quarto ano ajuda muito agora para estabelecer vínculos e [...] na habilidade de comunicação clínica em si [...] (E8 - quinta série).

Osprofessorestambém relatamqueo desenvolvimento da comunicação é gradual conforme a prática nos estágios, pois, segundo eles, o currículo integrado favorece a prática da comunicação logo no início do curso, possibilitando que os estudantes cheguem ao internato com essa habilidade mais fortalecida.

Bom, eu percebo assim, como currículo vem integrado desde primeiro ano, e ele trabalha com [...] entrada dele [do estudante] já na atenção básica, [...] eu percebo que a habilidade de comunicação ela vai se construindo através dos anos e ao chegar no internato a gente percebe diferencial dos nossos estudantes no sentido de ter essa comunicação mais desenvolvida (P5 - quinta e sexta séries).

Conforme orientado pelos cadernos das séries ${ }^{21,22}$, o estudante é inserido gradativamente no contexto de atuação para desenvolvimento do seu desempenho diante das necessidades apresentadas. A literatura aponta que a comunicação é competência clínica essencial para o cuidado integral. Segundo o estudo realizado por $\operatorname{Rios}^{23}$, esse processo educacional é gradativo, pois parte de contextos mais básicos até alcançar os mais complexos, a fim de desenvolver no estudante conhecimentos, habilidades e atitudes como base para comunicação efetiva.

Uma fragilidade apontada pelos estudantes referese ao fato de o desenvolvimento da comunicação ser bem trabalhado no início da graduação, porém, depois da terceira série, o predomínio é de uma abordagem mais teórica e sem treinamento ou disparadores.

[...] depois você vai se perdendo, no terceiro e no quarto ano nós não temos abordagem nesse sentido, então fica muito mais parte teórica, às vezes abre alguma coisa de comunicação, mas é muito raro [...], só depois você percebe que fez falta [...] (E12 - sexta série).

Para os professores, a falta de preparo do docente, com predomínio da formação biomédica em alguns casos, também é ponto de fragilidade apresentado: "o internato é uma fase muito difícil, [...] tem preceptores de [...] diversas especialidades, em diversos cenários, e muitas vezes o que é construído nos primeiros anos pode chegar a se fragmentar no internato" (P5 quinta e sexta séries).

A formação do professor no currículo integrado e orientado por competência é muito importante para que ele desempenhe papel de facilitador no aprendizado. Desenvolver autonomia nos estudantes e incentivar o processo ativo 
de aprendizagem são comportamentos esperados desse profissional. Ferreira et al. ${ }^{24}$ apontam que, na maioria das vezes, o professor é aquele profissional que apresenta afinidade pelo ensino e passa a exercer suas atividades acadêmicas pelos pressupostos de "aprender a ensinar ensinando", sendo guiado pelos modelos de outros professores que já atuam no ensino. Os autores refletem que, nesses casos, a docência é uma atividade secundária à profissão médica. Essa postura precisa ser repensada, pois pode trazer prejuízos à formação dos estudantes e dos professores ${ }^{24}$.

Dentro da perspectiva de valorização, os professores percebem dificuldade em colocar em prática a comunicação devido ao excesso de trabalho, à carga horária e à indevida valorização do profissional.

[...] excesso de trabalho, pouco tempo, má valorização dos profissionais, realmente fica muito difícil fazer isso. Bonito é [...] na teoria; na prática, a gente está com três horas para atender dúzias de pacientes com neoplasia, como que você vai dar atenção que o paciente precisa? É impossível (P3 - quinta série).

Novaes et al. ${ }^{25}$ avaliam que esses professores geralmente são médicos que trabalham na assistência, sem ter em seu currículo formação pedagógica, e refletem que, além da atuação como professor, esse profissional também exerce outras atividades em múltiplos cenários, o que pode comprometer a saúde mental dele ${ }^{25}$. Há, aqui, o conceito de secundarização do estatuto de profissão que ocorre quando o professor está inserido no ambiente de ensino, porém sem formação específica e com dificuldade na atuação didáticopedagógica. Canuto et al. ${ }^{26}$ refletem sobre a importância da valorização do professor nesse contexto, do investimento na formação dele e da discussão sobre o entendimento que ele tem de todo o processo. Os autores apontam ainda questões referentes à disponibilidade do professor para atuar em sala de aula e à valorização de seu papel na formação dos estudantes.

Os entrevistados ressaltam também que se observa desarticulação teórico-prática a partir da terceira série. A dificuldade na falta de padronização em cada cenário de prática e diferenças na demanda de atendimento também são fragilidades apontadas pelos professores.

Então, até a quarta série é tudo certinho, entendeu? [...] chega no internato, ele está monitorado, ele vai ter preceptor em todo lugar que ele estiver, [...] agora imagina você numa demanda de pronto-socorro, entendeu? Onde tem oitenta na fila, cinquenta numa maca, não sei quanto internado, e você tem que dar conta, ai se perde [...] (P7 - 6a série).

Como reflexões da prática pedagógica, percebeu-se na fala dos professores a importância do acompanhamento do estudante no cenário simulado. O desenvolvimento da habilidade de comunicação com o professor e o paciente, e o incentivo à habilidade de comunicar-se adequadamente e ser bom profissional fazem parte dessa prática na evolução da graduação: "desenvolvendo habilidade de comunicação maior, já que são realizados em grupos pequenos e todos têm que participar e falar. Você estimula o aluno a desenvolver essa habilidade de comunicação [...]" (P9 - quinta série).

Outra forma de prática pedagógica ressaltada aqui é incentivar a busca de informação sobre os pacientes para que o professor conheça a história e realize o acompanhamento. Entretanto, o estudante precisa do exemplo na prática. Para isso, a realização de visitas clínicas com os estudantes como construção da comunicação e o apoio oferecido a eles na síntese da anamnese fazem parte da prática pedagógica dos professores: "eles aprendem a fazer anamnese extremamente completa e na visita não dá, eles têm que aprender fazer síntese, e eu pergunto de propósito para ele perceber que faltou coisas" (P2 - quinta e sexta séries).

Para o desenvolvimento do pensamento crítico-reflexivo dos estudantes e a aquisição da aprendizagem teórico-prática, a presença do professor como mediador e facilitador desse processo é imprescindível. Esse movimento relacional e de interação proporciona a construção de conhecimento ${ }^{27}$.

Percebe-se nessa categoria que estudantes e professores entendem o processo de comunicação clínica, que deve ser desenvolvido no decorrer da graduação de forma crescente; contudo, ambos percebem fragmentação desse processo no internato por motivos de organização dos cenários, falta de preparo do professor e tempo hábil para tais movimentos.

\section{Proposições para a formação de estudantes e professores no internato}

Ao refletirem sobre fragilidades na organização do internato, estudantes e professores percebem que a prática da comunicação no internato é deficiente, pois há pouco estímulo a essa habilidade.

No começo da faculdade, no primeiro e segundo ano eles exigem que a gente enxergue paciente como todo [...] só que [...] no internato eles querem que você seja exatamente oposto disso, talvez porque médicos do internato [...] têm mentalidade diferente dos que atuam nos primeiros anos (E1 - quinta série).

Na perspectiva dos professores, no internato a integração do currículo não é tão bem trabalhada como nos primeiros anos da graduação.

Quando eles chegam ao quarto ano para quinto ano, eles chegam apavorados, [...] depois dá uma melhorada, e eu percebo que até o quarto ano tem 
espiritualidade, tem cobrança, tem respeitabilidade, tem condição de exigência, tem mecanismo de trabalho alique depois do quinto ano écompletamente diferente, não existe sequência que eu julgo ser razoável [...] (P8 - quinta série).

Os estudantes enfatizam o foco nos aspectos da esfera biológica. Relatam que as habilidades de comunicação já não são mais abordadas no internato, com ausência de avaliação personalizada e feedback para o desenvolvimento do estudante, o que amplia a dificuldade da comunicação nesse ambiente. Relatam que a avaliação, quando ocorre, é dependente do professor, sem algo sistematizado, visão que os professores compartilham:

[...] geralmente os alunos atendem o caso, [...] só depois vou ver com eles; muitas vezes, eu não acompanho exatamente como o aluno atendeu paciente, vejo depois e às vezes falta informações, dados que não foram perguntados, mas entrevistas em si, conversas com pacientes e com familiares são eles" (P9-quinta série).

Os estudantes relatam a falta de oportunidade em serem ouvidos e acolhidos por conta do conservadorismo e da dificuldade de alguns professores em propiciar espaço para essa aprendizagem por também, segundo os estudantes, apresentarem dificuldades em lidar com questões subjetivas dos pacientes.

[...] eles não estão muito dispostos ouvir. A [instituição] de certa forma até abre espaço maior para a gente falar, [...] então a gente tem abertura com eles, mas médico [...] é profissional que está acostumado a não receber ordens, eles dão ordens, eles têm mente mais conservadora e mais fechada, são menos abertos a mudanças (E1 - quinta série).

Segundo a vivência dos estudantes no internato, muitos professores acabam se voltando mais para assistência do que para ensino, fazendo com que não haja orientação de como proceder no ambiente intra-hospitalar, incluindo falta de comunicação com outras profissões da assistência: "ficamos muito fechados na equipe médica no internato, então, temos pouco contato, [...] por exemplo, hoje nós vemos através de [anamnese de] interconsultas, não vemos conversa, só vemos no sistema que foi 'canetado'"' (E3 - quinta série).

Os estudantes também se sentem inseguros em relação à condução dos casos devido à falta de homogeneidade na postura do professor ou do médico plantonista quanto à aprendizagem: "tem uns que vão ver paciente, tem outros que não vão, tem uns que não levantam da cadeira, sabe?, só falam para você fazer coisas. Já tem outros que vem e vê sua história, corrige, vai com você, examina, orienta, então tem dois perfis" (E17 - sexta série).
Outra fragilidade importante exposta por eles refere-se à existência de poucos professores para condução do internato, dificuldade que obriga os estudantes a "tocar serviço", com prejuízo ao processo de aprendizagem, com carga horária muito extensa: "O nosso problema no internato são estágios que são muitos desiguais, então tipo alguns estágios eles querem que realmente a gente toque serviço, então essa questão de aprendizado, de você desenvolver novas técnicas realmente não existe" (E7 - quinta série).

Um estudo que abordou a percepção do egresso sobre a avaliação de aprendizagem no internato médico mostra pontos de fragilidades na organização do internato, como avaliações baseadas em atributos pessoais e não de desempenho; falta de empatia e aproximação com o estudante; julgamento do professor pelo tempo nos atendimentos e não pela qualidade; e falta de objetivos traçados claramente para esse cenário. Como potencialidades, os estudantes foram muito enfáticos em relação ao feedback que os professores pontualmente prestavam a eles, além da avaliação diária sobre a prática no cenário. Esses dois pontos, segundo o estudo, foram fatores preponderantes na formação ${ }^{28}$.

Lima et al. ${ }^{29}$, em estudo realizado em uma universidade pública de Fortaleza, demonstram como potencialidade a importância do papel mediador e facilitador do professor no cenário do internato. Como fragilidades, apontam a falta de experiência dos professores com metodologias ativas, o distanciamento dos estudantes, a falta de discussão de casos, a alta demanda de usuários e o despreparo dos cenários em receber estudantes.

Uma possibilidade de melhoria explorada pelos estudantes é poder integrar melhor outras áreas profissionais de assistência ao usuário, a fim de desenvolver melhor a comunicação sistematizada ao longo da graduação, visão que é compartilhada pelos professores:

Não só melhoria da comunicação, mas talvez desenvolver ao longo dos quatro anos, seria uma conversa com os alunos ou mesmo um pouco mais de contato com o profissional que faz o atendimento ou tendo o atendimento, acho que seria uma boa maneira de melhorar essa comunicação [...] às vezes se você desenvolvesse antes, já tivesse uma certa habilidade para chegar no quinto com uma boa comunicação, talvez o ganho seria maior ao longo do internato (E5 - quinta série).

[...] a gente tinha equipe, passava vez por semana vários profissionais na enfermaria, e eu sempre trabalhava com eles com plano de alta no primeiro dia de internação. Eu vejo que isso tem que ser trabalhado entre docentes, muitas vezes o assistente não tem essa percepção, [...] é questão de formação [...], e nossa formação foi biomédica (P1 - sexta série). 
Pensando na qualidade de vida dos estudantes no internato, Meyer et al. ${ }^{30}$ discutiram esses aspectos e identificaram questões como fadiga, problemas em adaptar o sono e humor deprimido devido à dificuldade em conciliar horas práticas do internato com estudos. Também referem grande demanda de atendimentos no internato como geradora de sofrimento por falta de tempo nas discussões deles, impossibilitando um bom andamento dos estudos e da atuação prática.

Ainda como proposições para organização do internato, estudantes e professores sugerem investimento na remuneração, valorização profissional e contratação de professores.

A primeira coisa é a valorização [...] é uma coisa muito mais ampla, mas de uma forma mais simples eu acho que seria valorizar mais o profissional que está aqui com o salário, [...] quando o profissional é mal remunerado, ele não tem estímulo para continuar incentivando esse ensino completo (E4 - quinta série).

Os professores refletem sobre a importância do tempo hábil para discutir com estudantes e estar mais próximo deles na condução dos casos.

\section{[...] a visita para 30 pacientes tem que passar a manhã inteira e a tarde, só que a prática não funciona assim, muitas vezes você não consegue sentar com aluno, muitas vezes a gente pega dois ou três casos e conversa pouco melhor, às vezes um caso mais interessante, mas não dá para fazer isso com todos, pois é impossível (P3 - quinta série).}

Barreto et al. ${ }^{31}$ também demonstram essas fragilidades do contato com estudante, devido à formação do docente em metodologia diferente, justificando a necessidade de capacitação para poder atuar na mediação da aprendizagem dos discentes.

Considerando o que foi exposto, percebe-se necessidade de proposta de gestão de currículo, do PPC e de gestão de pessoas para que mudanças acerca do processo de preceptoria possam ser implementadas no internato no que tange à comunicação clínica.

\section{CONCLUSÕES}

Os resultados mostram a percepção de estudantes e professores acerca da comunicação clínica e da proposta curricular da instituição, revelando que compreendem o conceito e a importância dessa competência para a formação e prática profissionais. Em contrapartida, ambos relatam lacunas no desenvolvimento dessa habilidade na graduação, evidenciando dificuldades na operacionalização do currículo utilizado pela faculdade.

Revelam também a importância do entendimento de conceitos sobre a formação e prática profissionais dos estudantes, porém demonstram dificuldades referentes ao papel de mediador e facilitador que o professor exerce dentro dessa proposta curricular.

Quando se avaliaram as proposições dos estudantes, levantaram-se demandas acerca da estruturação do currículo no que diz respeito à presença e ao fortalecimento do papel do professor como mediador no processo de formação, assim como a necessidade de contínuo feedback e a possibilidade de haver um espaço para que possam refletir sua prática com o apoio dos professores que atuam na comunicação, como acontece nos primeiros anos. Pode-se pensar na construção de diretrizes para intervenção e formalização no projeto pedagógico e eixo curricular das séries do curso, buscando o fortalecimento de espaço de escuta para os estudantes do internato refletirem sua prática e poderem, por meio desse movimento e estratégia, significar ainda mais seu aprendizado.

Em relação às colocações dos professores, houve emergência de demandas em relação à valorização profissional e à carga horária de trabalho que dedicam à formação dos estudantes dentro da proposta curricular. Pode-se pensar em intervenções no sentido da valorização de todo empenho do professor nesse processo.

O estudo deu origem a dois projetos de intervenção: uma oficina de reflexão para os professores de todas as séries da instituição e uma oficina de construção com os estudantes para a proposição curricular.

A exploração da temática em currículo integrado e na abordagem dialógica de competência poderá não apenas contribuir para futuras estratégias locais e outras experiências, uma vez que a temática é abordada nas DCN do curso de Medicina, mas também poderá trazer contribuições para outras carreiras da área da saúde.

\section{CONTRIBUIÇÃO DAS AUTORAS}

Ana Glaucia Paulino Lima participou da conceptualização do estudo, da organização dos dados, da análise formal, pesquisa, metodologia e administração do projeto, dos recursos e da validação e visualização do resultado final. Danielle Abdel Massih Pio participou da conceptualização do estudo, da organização dos dados, da análise formal, pesquisa, metodologia e administração do projeto, dos recursos, da supervisão da pesquisa, e da validação, visualização, redação, revisão e edição do texto. Ana Carolina Nonato participou da organização dos dados, e da visualização, redação, revisão e edição do texto. Mara Quaglio Chirelli e Roseli Vernasque Bettini participaram da supervisão, validação e visualização do projeto.

\section{CONFLITO DE INTERESSES}

Declaramos não haver conflito de interesses. 


\section{FINANCIAMENTO}

Declaramos não haver financiamento.

\section{REFERÊNCIAS}

1. Griffin E, Ledbetter A, Sparks G. A first look at communication theory. 10th ed. New York: McGraw-Hill Education; 2019. 475 p.

2. Monteiro DT, Quintana AM. A comunicação de más notícias na UTI: perspectiva dos médicos. Psicol Teor Pesqui. 2016;32(4):1-9 [access in 19 oct 2020]. Available from: http://www.scielo.br/scielo.php?script=sci_ arttext\&pid=S0102-37722016000400221\&lng=pt\&tlng=pt.

3. Morais GS N, da Costa SFG, Fontes WD, Carneiro AD. Comunicação como instrumento básico no cuidar humanizado em enfermagem ao paciente hospitalizado. Acta Paul Enferm. 2009;22(3):323-7 [access in 20 oct 2020]. Available from: http://www.scielo.br/scielo.php?script=sci_ arttext\&pid=S0103-21002009000300014\&lng=pt\&tlng=pt.

4. Sucupira AC. A importância do ensino da relação médico-paciente e das habilidades de comunicação na formação do profissional de saúde. Interface Comun Saúde Educ. 2007;11(23):624-7 [access in 20 oct 2020]. Available from: http://www.scielo.br/scielo.php?script=sci_ arttext\&pid=S1414-32832007000300016\&lng=pt\&tlng=pt.

5. Teixeira JAC. Comunicação em saúde: relação técnicos de saúde-utentes. Anál Psicol. 2004;22(3):615-20 [access in 19 oct 2020]. Available from: http://www.scielo.mec.pt/scielo.php?script=sci_abstract\&pid=S0870$82312004000300021 \&$ lng =p\&nrm=iso\&tlng=pt.

6. Brasil. Resolução CNE/CES no 4, de 7 de novembro de 2001. Institui Diretrizes Curriculares Nacionais do Curso de Graduação em Medicina. Brasília: Conselho Nacional de Educação, Câmara de Educação Superior; 2001. Available from: http://portal.mec.gov.br/cne/arquivos/pdf/CES04.pdf.

7. Brasil. Resolução $n^{\circ} 3$, de 20 de junho de 2014. Institui Diretrizes Curriculares Nacionais do Curso de Graduação em Medicina e dá outras providências. Brasília: Ministério da Educação, Conselho Nacional de Educação Superior, Câmara de Educação Superior; 2014 [access in 23 oct 2020]. Available from: http://portal.mec.gov.br/index.php?option=com _ docman\&view=download\&alias $=15874-$ rces003-14\&category slug=junho-2014-pdf\&ltemid=30192.

8. Chirelli MQ, Nassif JV. Avaliação critério-referenciada: acompanhamento do estudante no currículo orientado por competência. Rev Pesqui Qual. 2019;7(14):169-192 [access in 20 oct 2020]. Available from: https://editora. sepq.org.br/index.php/rpq/article/view/264.

9. Faculdade de Medicina de Marília. Projeto Pedagógico do Curso de Medicina. Marília: Famema; 2014 [access in 19 out 2020]. Available from: http://www.famema.br/ensino/cursos/docs/PPC Medicina.pdf.

10. Jucá NBH, Gomes AMA, Mendes LS, Gomes DM, Martins BVL, Silva CMGC, et al. A comunicação do diagnóstico "sombrio" na relação médicopaciente entre estudantes de Medicina: uma experiência de dramatização na educação médica. Rev Bras Educ Med. 2010;34(1):57-64 [access in 22 oct 2020]. Available from: http://www.scielo.br/scielo.php?script=sci_ arttext\&pid=S0100-55022010000100007\&lng=pt\&tlng=pt.

11. Rossi PS, Batista NA. O ensino da comunicação na graduação em medicina: uma abordagem. Interface Comun Saúde Educ. 2006;10(19):93-102 [access in 21 oct 2020]. Available from: http://www.scielo.br/scielo.php?script=sci_ arttext\&pid=S1414-32832006000100007\&lng=pt\&tlng=pt.

12. Ferreira RC, Tsuji H, Tonhom SFR. Aprendizagem baseada em problemas no internato: há continuidade do processo de ensino e aprendizagem ativo? Rev Bras Educ Med. 2015;39(2):276-85 [access in 20 oct 2020]. Available from: http://www.scielo.br/scielo.php?script=sci arttext\&pid=S0100-55022015000200276\&lng=pt\&tlng=pt.

13. Faculdade de Medicina de Marília. Caderno de avaliação: cursos de medicina e enfermagem. Marília: Famema; 2020.

14. Minayo MCS. Amostragem e saturação em pesquisa qualitativa: consensos e controvérsias. Rev Pesqui Qual. 2017;5(7):1-12 [access in 20 oct 2020]. Available from: https://editora.sepq.org.br/index.php/rpq/ article/view/82
15. Bardin L. Análise de conteúdo. São Paulo: Edições 70; 2011. 280 p

16. Minayo MCS. O desafio do conhecimento: pesquisa qualitativa em saúde. 13th ed. São Paulo: Hucitec; 2013. 407 p.

17. Vogel KP, da Silva JHG, Ferreira LC, Machado LC. Comunicação de más notícias: ferramenta essencial na graduação médica. Rev Bras Educ Med. 2019;43(1 sup 1):314-21 [access in 24 oct 2020]. Available from: http://www.scielo.br/scielo.php?script=sci_arttext\&pid=S0100 55022019000500314\&tlng=pt

18. Rocha SR, Romão GS, Setúbal MSV, Collares CF, Amaral E. Avaliação de habilidades de comunicação em ambiente simulado na formação médica: conceitos, desafios e possibilidades. Rev Bras Educ Med. 2019;43(1 sup 1):236-45 [access in 24 oct 2020]. Available from: http://www.scielo.br/ scielo.php?script=sci_arttext\&pid=S0100-55022019000500236\&tlng=pt.

19. Braga RL, Carozzo NPP, Cardoso BLA, Teixeira CM. Avaliação da comunicação médico-paciente na perspectiva de ambos interlocutores. Salud(i)Ciencia. 2020;23(8):668-72.

20. Cotta Filho CK, Miranda FBG, Oku H, Machado GCC, Pereira Junior GA Mazzo A. Cultura, ensino e aprendizagem da empatia na educação médica: scoping review. Interface Comun Saúde Educ. 2020;24(e180567):1 15 [access in 24 oct 2020]. Available from: http://www.scielo.br/scielo. php?script=sci_arttext\&pid=S1414-32832020000100300\&tlng=pt.

21. Faculdade de Medicina de Marília. Estágio integrado: Saúde do Adulto I, Saúde Materno-Infantil I. Marília: Famena; 2020 [access in 20 oct 2020] Available from: http://www.famema.br/ensino/cursos/docs/Caderno $\% 20$ da\%205\%C2\%AA\%20s\%C3\%A9rie\%20de\%20Medicina.pdf.

22. Faculdade de Medicina de Marília. Estágio integrado: Saúde do Adulto II, Saúde Materno-Infantil II. Marília: Famena; 2020 [access in 20 oct 2020] Available from: http://www.famema.br/ensino/cursos/docs/Caderno\%20 de $\% 20$ S\%C3\%A 9rie \% 20-\%206\%C2\%AA\%20s\%C3\%A9rie\%20 Medicina\%202020.pdf

23. Rios IC. Comunicação em medicina. Rev Med. 2012;91(3):159-62.

24. Ferreira CC, Souza AML. Formação e prática do professor de medicina: um estudo realizado na Universidade Federal de Rondônia. Rev Bras Educ Med. 2016;40(4):635-43 [access in 24 oct 2020]. Available from http://www.scielo.br/scielo.php?script=sci_arttext\&pid=S010055022016000400635\&lng=pt\&tlng=pt.

25. Novaes MRCG, César BN, Moura TR. Desgaste laboral em docentes de medicina: uma revisão de literatura. Brasília Méd. 2013;50(2):111-7.

26. Canuto AMM, Batista SHSS. Concepções do processo ensinoaprendizagem: um estudo com professores de medicina. Rev Bras Educ Med. 2009;33(4):624-32 [access in 21 oct 2020]. Available from: http://www.scielo.br/scielo.php?script=sci_arttext\&pid=S010055022009000400013\&lng=pt\&tlng=pt.

27. Chirelli MQ, Nassif JV. O processo ensino-aprendizagem em metodologia ativa: visão do professor no currículo integrado e por competência dialógica. Indagatio Didact. 2017;9(3):61-77 [access in 20 oct 2020]. Available from: https://proa.ua.pt/index.php/id/article/view/619.

28. Leonel IM, Sanches LC, de Campos JJB, Esteves RZ. A percepção do egresso sobre a avaliação de aprendizagem no internato médico de saúde coletiva. Rev Saúde Pública Paraná. 2019;20(1):48-61.

29. de Lima ICV, Shibuya BYR, Peixoto MGB, de Lima LL, Magalhães PSF. Análise do internato em medicina da família e comunidade de uma universidade pública de Fortaleza-CE na perspectiva do discente. Rev Bras Educ Med. 2020;44(1):1-8 [access in 23 oct 2020]. Available from: http://www.scielo.br/scielo.php?script=sci_arttext\&pid=S010055022020000100203\&tlng=pt.

30. Meyer C, Barbosa DG, Andrade RD, Ferrari Junior GJ, Gomes Filho Neto $M$, Guimarães $A C$, et al. Qualidade de vida de estudantes de medicina e a dificuldade de conciliação do internato com os estudos. ABCS Heal Sci. 2019;44(2):108-13 [access in 24 oct 2020]. Available from: https://www. portalnepas.org.br/abcshs/article/view/1169.

31. Barreto VHL, De Marco MA. Visão de preceptores sobre o processo de ensino-aprendizagem no internato. Rev Bras Educ Med. 2014;38(1):94102 [access in 24 oct 2020]. Available from: http://www.scielo.br/scielo. php?script=sci_arttext\&pid=S0100-55022014000100013\&lng=pt\&tlng=pt. 